\title{
AVALIAÇÃO DA QUALIDADE DA ÁGUA DOS PESQUE- PAGUE LOCALIZADOS NA BACIA DO RIO CORUMBATAÍ, SP (BRASIL)
}

\section{WATER QUALITY EVALUATION IN THE FEE-FISHING LOCATED IN CORUMBATAI RIVER BASIN, SP (BRAZIL)}

\author{
Ítalo Macedo Silva ${ }^{1}$, Sâmia Maria Tauk-Tornisielo ${ }^{2}$, \\ Alexandre Augusto Oliveira Santos ${ }^{3}$, Eleni Nadai Malagutti ${ }^{4}$ \\ ${ }^{1}$ Mestre, Centro de Estudos Ambientais da Universidade Estadual Paulista, Campus \\ de Rio Claro, SP. E-mail: ytalo@ymail.com \\ ${ }^{2}$ Pesquisadora do Centro de Estudos Ambientais da Universidade Estadual Paulista, \\ Campus de Rio Claro, SP. E-mail: seb@rc.unesp.br \\ ${ }^{3}$ Doutor em Limnologia, Centro de Estudos Ambientais da Universidade Estadual \\ Paulista, Campus de Rio Claro, SP. E-mail: alexbio2002@yahoo.com.br \\ ${ }^{4}$ Biomédica, Centro de Estudos Ambientais da Universidade Estadual Paulista, \\ Campus de Rio Claro, SP. E-mail: eleninm@rc.unesp.br
}

\begin{abstract}
RESUMO
Os pesque-pague são unidades compostas por viveiros, onde são criados peixes utilizados em pesca esportiva. Nos viveiros, a estocagem dos peixes pode deteriorar a qualidade da água com o enriquecimento de nutrientes, provenientes da ração, fertilização e das fezes dos peixes e animais do entorno. Este trabalho determinou algumas das variáveis bióticas dos efluentes e dos corpos de água superficiais relacionados diretamente com as unidades de pesque-pague. Inicialmente foi realizado um diagnóstico do número de pesque-pague em atividade na bacia do rio Corumbataí. Posteriormente, foram escolhidos 6 estabelecimentos para monitoramento bimestral, realizado em 9 coletas. Foram coletadas amostras de água dos viveiros para analisar as variáveis DBO, pigmentos totais, coliformes totais, E. coli, e realizados testes de toxicidade. Foi aplicada análise de componentes principais aos valores das variáveis bióticas dos pesque-pague estudados. Os resultados foram comparados com os limites estabelecidos, pela legislação vigente. Foram encontrados 14 pesque-pague em funcionamento na bacia do rio Corumbataí, dos quais foram selecionados os 6 posteriormente monitorados. A maioria das variáveis aqui determinadas esteve com valores acima do limite estabelecido pela legislação vigente, demonstrando a necessidade de maior controle desses viveiros e de estabelecimento de passivo ambiental para este tipo de atividade.
\end{abstract}

Palavras-chave: Impactos ambientais. Piscicultura. Limnologia. Análise de componentes principais. 


\begin{abstract}
The fee-fishing are comprised of ponds, where fish are raised used in sport fishing. In ponds, the stocking of fish may deteriorate the water quality with the enrichment of nutrients from feed, fertilizer and fish faeces and animals around. This study determined some of the biotic factors of effluent and surface water bodies directly related units fee-fishing. Initially it carried out a number of fee-fishing active in Corumbataí river basin. Subsequently, six fee-fishing were selected for monitoring bi-monthly, this carried out in nine samples. It collected samples of pond water to analyze the parameters: DBO, total pigments, total coliforms, E.coli, and toxicity tests. It was applied a principal component analysis to the values of the biotic fee-fishing studied. Most of the factors determined here were above the limit established by that law, demonstrating the need for greater control of ponds and the establishment of an Environmental Liability for this kind of activity.
\end{abstract}

Keywords: Environmental impacts. Fish farming. Limnology. Principal component analysis.

\title{
1. INTRODUÇÃO
}

Os pesque-pague são estabelecimentos suburbanos ou rurais que dispõem de lagos, onde são criadas espécies de peixes apreciadas pelos pescadores amadores. Estes podem usufruir horas de lazer com o material de pesca, mediante pagamento ao proprietário, de taxa e/ou remuneração conforme o peso total de peixes capturados. Este tipo de atividade tem atraído muitos pescadores, sendo responsável pelo aumento expressivo do mercado de pesca amadora.

Apesar de vários aspectos que ainda precisam ser monitorados e corrigidos, os pesque-pague são pontos de encontros de pessoas que fogem do corre-corre das cidades e buscam peixes mais frescos do mercado. Eles constituem também uma opção de lazer, descanso e diversão para toda a família (TAUK-TORNISIELO, 2010).

$\mathrm{Na}$ piscicultura, a qualidade da água em condições inadequadas prejudica o crescimento, reprodução e saúde dos peixes, favorecendo o aparecimento de sabores e odores indesejáveis que contribuem negativamente para o comércio desses produtos. Kubitza (2003) citou que as variáveis físicas, químicas e biológicas determinam a qualidade da água nos viveiros. Nessa atividade, a frequência do fornecimento de alimento é um fator importante dentro do manejo alimentar por estimular o peixe a procurá-lo em momentos predeterminados. Esse tipo de manejo pode contribuir para a redução na conversão alimentar, incrementar o ganho de peso dos peixes, além de possibilitar maior oportunidade de observação destes quanto ao estado de saúde.

Os efluentes da piscicultura são frequentemente mais concentrados em sólidos em suspensão, nutrientes e materiais orgânicos (BOYD e QUEIROZ, 1997), os quais, quando em excesso, acarretam oxidação bacteriana que pode levar a condições de anoxia na água. Os dejetos liberados pelos peixes modificam as características físicas, químicas e biológicas dos viveiros. Esses resíduos orgânicos, após ação microbiológica, fornecem nutrientes essenciais para o desenvolvimento de plâncton e de macrófitas aquáticas, podendo, quando em excesso, causar eutrofização do ambiente e alteração da composição e abundância de diversos organismos aquáticos (PÁDUA, 2001).

Castellani (2002), estudando os pesque-pague da região do Vale do Ribeira, concluiu que o maior teor de nutrientes verificado no efluente dos viveiros é, provavelmente, devido ao excesso de ração, degradando a qualidade da água. Também para Ono e Kubitza (1999), os resíduos fecais e sobras de ração são as principais fontes de resíduos orgânicos nos sistemas de produção.

O objetivo deste estudo foi realizar a análise das variáveis bióticas e comparar os resultados com os limites estabelecidos pela resolução CONAMA para água doce de classe 2, na qual se enquadra os efluentes dos pesque-pague estabelecidos na bacia do rio Corumbataí. 


\section{MATERIAL E MÉTODOS}

Esse trabalho foi realizado no Estado de São Paulo, na bacia do rio Corumbataí, que engloba os municípios de Analândia, Itirapina, Corumbataí, Rio Claro, Charqueada, Ipeúna, Santa Gertrudes e Piracicaba, além de diversos distritos como Ferraz, Ajapí, Assistência e Recreio (Figura 1).

Os pesque-pague foram inicialmente identificados baseando-se em informações de proprietários e frequentadores, além daquelas sobre as localizações fornecidas por moradores das cidades visitadas. Na época não havia cadastro oficial em órgãos do Estado ou prefeituras. Foi então construído um mapa da localização dos pesque-pague, com base nas informações aferidas com o auxílio de GPS (Figura 1).

Foram visitados 14 pesque-pague em toda a extensão da bacia do rio Corumbataí - SP, realizando-se análise diagnóstica inicial da qualidade da água destas unidades. Quando possível foi coletada água da entrada e na saída dos viveiros, pois alguns deles foram construídos em cima da mina de água; nesses não foram possíveis as coletas de água de abastecimento. Após a análise diagnóstica e verificação da qualidade da água, os pesque-pague foram divididos em extratos: origem da água de abastecimento (mina, poço artesiano) e área hídrica (pequeno, médio e grande). Foi sorteado 1 pesque-pague representativo para cada extrato previamente definido, onde estudos mais detalhados foram realizados em 6 deles. Estes foram monitorados bimensalmente em 9 coletas, durante 20 meses.

As amostras de água de abastecimento e dos efluentes dos viveiros foram coletadas com o auxílio de frascos de polietileno de $500 \mathrm{~mL}$ previamente limpos, a $15 \mathrm{~cm}$ de profundidade, os quais foram estocados em caixas térmicas na sombra, para posterior análise de coliformes totais, Escherichia coli (E. coli), clorofila a, demanda bioquímica de oxigênio (DBO) e toxicidade.

As amostras destinadas às análises microbiológicas de $E$. coli e coliformes totais foram coletadas em frascos plásticos, previamente esterilizados em autoclave a $121^{\circ} \mathrm{C}$ e $1 \mathrm{~atm}$, durante 30 min. Essas duas variáveis foram determinadas com a técnica de Colilert (APHA, 1998). As amostras de água destinadas às análises de DBO foram coletadas em frascos âmbar, do tipo Pyrex, padrão para esse tipo de metodologia, a Incubação/Winkler (APHA, 1998). 


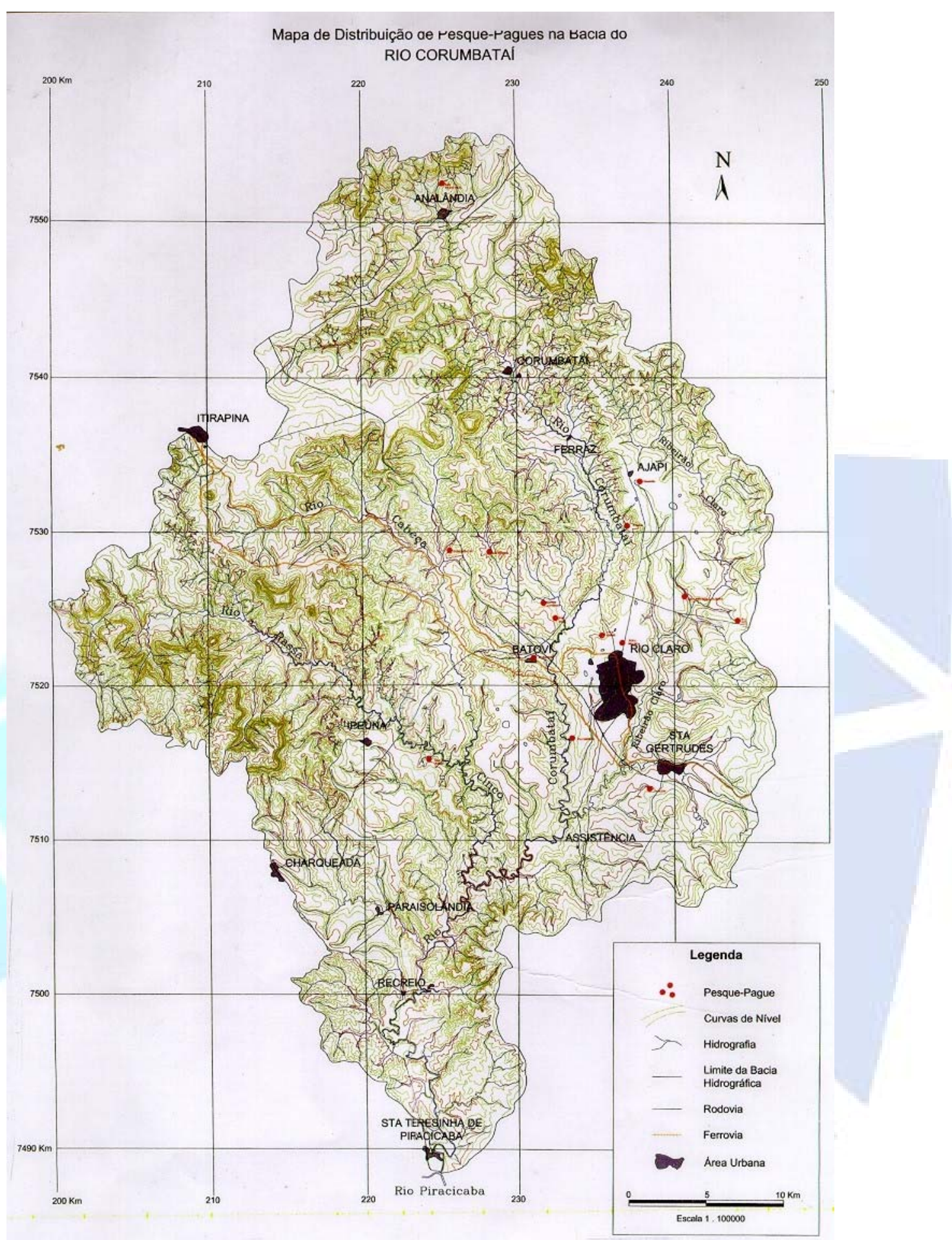

FIGURA 1. Mapa de localização dos pesque-pague na bacia do rio Corumbataí, SP. Fonte: Santos (2006)

Para as análises de clorofila a, as amostras foram acondicionadas em frascos de polietileno, com tampa, limpos com solução sulfocrômica e ácido clorídrico a 10\%. A análise foi realizada com a técnica espectrofotométrica colorimétrica. A amostra possui a mistura de clorofila e seus produtos de decomposição (feofitina, feoforbidos), carotenos e xantofilas, assim como pigmentos fotossintéticos de bactérias, folhas mortas, etc. A medição dessa variável foi realizada após extração com etanol, e calculada com seguinte fórmula: 


\section{Clorofila a $(\mu \mathrm{g} / \mathrm{L})=\left[\left(\mathrm{U}_{\mathrm{E} 663}-\mathrm{U}_{\mathrm{E} 750}\right) \cdot \mathbf{1 0 0 0} \cdot \mathrm{v}\right] / \mathrm{C} \cdot \mathrm{K} \cdot \mathrm{V}$}

$\mathrm{U}_{\mathrm{E} 663}$ é a leitura de absorbância a $663 \mathrm{~nm}, \mathrm{U}_{\mathrm{E} 750}$ é a leitura de absorbância a $750 \mathrm{~nm}, 1000$ é o fator de correção de alíquota para litros, v é o volume extraído $(\mathrm{mL}), \mathrm{C}$ é o caminho óptico $(\mathrm{cm})$, $\mathrm{K}$ é o coeficiente de extinção da luz e V é o volume filtrado (L).

Se a leitura de $\mathrm{U}_{\mathrm{E} 750}$ for maior, o resultado será negativo confirmando a interferência de feopigmentos no resultado (MARKER et al., 1980).

Os ensaios de toxicidade aguda foram realizados com a exposição de Daphnia similis aos efluentes dos pesque-pague estudados, sem a necessidade de diluição (CETESB, 1991).

Os procedimentos multivariados, k-médias e componentes principais foram aplicados às referidas variáveis bióticas das águas com valores padronizados, resultando em média nula e variância unitária (HARTINGAN, 1975). Foi aplicada análise de componentes principais (ACP) aos pesque-pague em relação às variáveis avaliadas. As análises foram realizadas com o auxílio do programa Statistica, versão 7.1 (STATSOFT, 2005).

Os resultados foram comparados aos padrões estabelecidos na Resolução CONAMA n ${ }^{\circ}$ 357/2005 (BRASIL, 2005) para as variáveis DBO e clorofila a. Para as variáveis coliformes totais e E. coli, os valores encontrados foram comparados com 5.000 org. $100 \mathrm{~mL}^{-1}$ e $1.000 \mathrm{org} \cdot 100 \mathrm{~mL}^{-1}$, respectivamente, considerados como os limites máximos para o presente trabalho.

\section{RESULTADOS E DISCUSSÃO}

\subsection{Diagnóstico inicial}

Os resultados obtidos quanto às variáveis bióticas da qualidade da água dos viveiros dos pesque-pague na bacia do rio Corumbataí, no diagnóstico inicial realizado durante dois meses, estão representados na Tabela 1. Apesar de terem sido encontrados 16 pesque-pague, os resultados citados somente se referem a 14 deles, pois dois deles tiveram suas atividades encerradas logo no início deste estudo.

Os valores encontrados para coliformes totais variaram entre 86,00 e 24.192,00 org. $100 \mathrm{~mL}^{-1}$, intervalo próximo àquele verificado na microbacia do córrego da Barriga, onde se encontra a Represa Velha, ou seja, $178,5 \mathrm{org} \cdot 100 \mathrm{~mL}^{-1}$ na nascente e $24.192,0 \mathrm{org} \cdot 100 \mathrm{~mL}^{-1}$ no interior da mata ciliar localizada no Instituto Chico Mendes, Pirassununga, SP (BUFON, 2002). A presença de coliformes totais em água deve ser interpretada de acordo com o tipo desta e indica algum tipo de contaminação, no entanto, a presença de E.coli demonstra certamente a poluição fecal, proveniente de fezes de animais de sangue quente ou de esgotos (NOUR apud BUFON, 2002).

As amostras analisadas nos pesque-pague em estudo praticamente apresentaram valores acima de 5.000 org. $\cdot 100 \mathrm{~mL}^{-1}$, considerado como o limite máximo permitido pela legislação vigente. Um dos pesque-pague (PP9) possui situação preocupante, pois a mina que abastece esta unidade possivelmente está sendo contaminada, excedendo em muito a este limite. 
TABELA 1 - Variáveis quantificadas no diagnóstico inicial da qualidade da água de todos os pesque-pague quanto às variáveis bióticas, na bacia do rio Corumbataí (coletas entre março 2005 e novembro de 2006).

\begin{tabular}{|c|c|c|c|c|c|}
\hline Estabelecimentos & $\begin{array}{c}\text { Coliformes Totais } \\
\text { NMP.100 } \mathrm{mL}^{-1}\end{array}$ & $\begin{array}{c}\text { E. coli } \\
\text { NMP.100 mL } \text { mL }^{-1}\end{array}$ & $\begin{array}{c}\text { DBO } \\
\text { mg. } \mathrm{L}^{-1}\end{array}$ & $\begin{array}{c}\text { Clorofila a } \\
\mu \mathrm{g} . \mathrm{L}^{-1}\end{array}$ & Toxicidade \\
\hline \multicolumn{6}{|c|}{ e } \\
\hline PP1 Saída & $24.192,00$ & 387,30 & 15,00 & 84,64 & NT \\
\hline PP2 Entrada & $12.033,00$ & 547,50 & 11,60 & nd & NT \\
\hline PP2 Saída & $3.441,00$ & 19,50 & 13,10 & 59,93 & NT \\
\hline PP3 Saída & $6.910,00$ & 365,40 & 11,00 & 32,21 & NT \\
\hline PP4 Saída & $14.136,00$ & 125,90 & 12,70 & 14,23 & NT \\
\hline PP6 Entrada & $4.352,00$ & 344,80 & 9,30 & nd & NT \\
\hline PP6 Saída & $6.240,00$ & 59,10 & 9,70 & 0,75 & NT \\
\hline PP7 Saída & $6.867,00$ & 30,10 & 14,70 & 48,69 & NT \\
\hline PP8 Saída & $10.500,00$ & 461,10 & 9,10 & nd & NT \\
\hline PP9 Entrada & $24.192,00$ & 103,90 & 10,30 & nd & NT \\
\hline PP9 Saída & $9.208,00$ & 7,40 & 11,30 & 5,99 & NT \\
\hline \multicolumn{6}{|l|}{ Corumbataí } \\
\hline PP10 Saída & $6.867,00$ & 5,20 & 15,00 & 18,73 & NT \\
\hline PP11 Saída & $10.462,00$ & 33,20 & 9,10 & 16,48 & NT \\
\hline \multicolumn{6}{|l|}{ Santa Gertrudes } \\
\hline PP12 Saída & $3.873,00$ & 150,00 & 6,00 & 6,74 & NT \\
\hline \multicolumn{6}{|l|}{ Analândia } \\
\hline PP13 Entrada & $18.500,00$ & 410,60 & 23,30 & 108,61 & NT \\
\hline \multicolumn{6}{|l|}{ Ipeúna } \\
\hline PP14 Entrada & $2.500,00$ & 63,00 & 6,60 & 14,23 & NT \\
\hline PP14 Saída & $6.867,00$ & 86,00 & 5,40 & 24,80 & NT \\
\hline PP15 Entrada & $8.664,00$ & 20,00 & 6,40 & 8,99 & NT \\
\hline PP15 Saída & $3.654,00$ & nd & 8,00 & 16,48 & NT \\
\hline
\end{tabular}

$\mathrm{NT}=$ não tóxico; $\mathrm{nd}=$ não detectado; $\mathrm{DBO}=$ demanda bioquímica de oxigênio

Há necessidade de controle rigoroso, pois, em anos anteriores, essa mina foi proposta pelos seus próprios proprietários como fonte de água mineral. Naquela ocasião foram solicitadas algumas medidas mitigadoras para evitar a contaminação da mina, principalmente por fezes de aves. Além disso, outras fontes de contaminação podem ser oriundas do fato da mina estar localizada na base de um declive acentuado, onde foi permitido pela Prefeitura Municipal o estabelecimento de um loteamento para construção de residências, sem qualquer estrutura de saneamento básico, em sua plataforma superior. É possível que parte do esgoto possa estar sendo percolado por gravidade até chegar à mina.

Quanto aos valores de E. coli, pode ser verificado que em nenhum pesque-pague foi encontrado números maiores do que o limite máximo, considerado para este trabalho, de 1.000 org. $\cdot 100 \mathrm{~mL}^{-1}$, segundo a Resolução CONAMA n ${ }^{0}$ 357/2005 (BRASIL, 2005). Isto significa que não há grandes quantidades de fezes de animais de sangue quente nas águas dos viveiros em estudo.

Os valores da DBO estiveram acima daquele estabelecido por esta mesma Resolução citada no parágrafo anterior, cujo limite para água doce de classe 2 é de 5,0 mg. $\mathrm{L}^{-1}$. No pesque-pague PP13, o valor de DBO foi igual a 23,3 mg. $\mathrm{L}^{-1}$, superior ao limite determinado pela legislação vigente, o que reforça a necessidade de tratamento do efluente gerado. No geral, os valores encontrados podem ser considerados altos, o que indica a presença de grande quantidade de matéria 
orgânica em decomposição presente nesses viveiros. A explicação para esse fato pode estar relacionada à decomposição do excesso de ração não utilizada pelos peixes, fezes de animais, além de outras variáveis. Dessa forma, se tornam necessários estudos que avaliem a influência efetiva dessas variáveis na qualidade da água.

A maioria dos pontos de coleta apresentou valores de clorofila a abaixo do limite estabelecido pela Resolução CONAMA já citada, ou seja, $30 \mu \mathrm{g} . \mathrm{L}^{-1}$ de clorofila a, portanto, estando controlados em relação à quantidade de algas em seus viveiros. Este valor, no entanto, foi ultrapassado em 6 dos pesque-pague estudados. Em um deles, o valor de $108 \mu \mathrm{g}$. $\mathrm{L}^{-1}$, também ficou acima dos valores encontrados por Tucci-Moura (1996) no Lago das Garças, considerado eutrófico $\left(100 \mu \mathrm{g} . \mathrm{L}^{-1}\right)$.

Os resultados indicaram que as águas analisadas não apresentaram toxicidade aguda ao microcrustáceo Daphnia similis utilizado no teste, sendo que todas as amostras se apresentaram não tóxicas. Isso significa que os pesque-pague estudados, provavelmente, não utilizaram composto químico ou medicamento que apresentasse ecotoxicidade durante o período de estudo, segundo a metodologia aqui usada. Isso é um bom sinal, visto que, em trabalho semelhante, Eler e Espíndola (2006) constataram que 7 dos 22 pontos de coleta estudados apresentaram toxicidade crônica, e em alguns casos chegando a 100\% de imobilidade do crustáceo.

\subsection{Monitoramento Bimensal}

Após o diagnóstico inicial dos pesque-pague (Tabela 1), foi realizado o monitoramento de 5 pesque-pague: PP1, PP4, PP9, PP10 e PP15, e de mais um (PP5) que estava fechado durante o levantamento inicial, durante 20 meses. Os resultados das análises para coliformes totais nas coletas realizadas durante o monitoramento bimensal encontram-se na Tabela 2.

Os resultados de coliformes totais no monitoramento bimensal demonstraram que todos os pesque-pague apresentaram valores acima de 5.000 org. $100 \mathrm{~mL}^{-1}$. Apenas nas entradas dos pesquepague PP5 e PP15 houve valores abaixo deste limite, em quase todas as coletas. No primeiro foram observados altos valores em 2 coletas, coincidindo com a interrupção do fluxo da entrada, sendo aberto somente no momento da coleta. Também foi verificado alto valor desta variável na entrada do PP9, resultado preocupante, uma vez que os viveiros nesse pesque-pague são mantidos com água de mina, ou seja, subterrânea. Isso reforça a hipótese de que essa mina possa estar recebendo contaminação de alguma fonte, e essa pode estar de alguma forma relacionada a habitações do entorno. O desvio padrão desses resultados pode ser considerado alto, visto que os valores encontrados nas coletas realizadas foram completamente heterogêneos; isso também está refletido nas demais variáveis estudadas.

Comparando-se estes resultados citados na Tabela 2 com aqueles obtidos por Eler e Espíndola (2006) em pesque-pague da bacia do rio Mogi Guaçu, verificou-se que os valores aqui encontrados variaram entre 8.000 org. $100 \mathrm{~mL}^{-1}$ e 2.000 .000 org. $100 \mathrm{~mL}^{-1}$, muito próximos daqueles observados por esses autores. 
TABELA 2 - Resultados das médias e desvio-padrão (desvp) para coliformes totais (NMP.100 $\mathrm{mL}^{-1}$ ), E. coli (NMP.100 mL $\left.\mathrm{m}^{-1}\right)$, DBO (mg. $\left.\mathrm{L}^{-1}\right)$ e clorofila a $\left(\mu \mathrm{g} . \mathrm{L}^{-1}\right)$ da água dos pesque-pague monitorados na bacia do rio Corumbataí.

\begin{tabular}{|c|c|c|c|c|c|c|c|c|}
\hline \multirow[t]{2}{*}{ Pesque-pague } & \multicolumn{2}{|c|}{$\begin{array}{l}\text { Coliformes totais } \\
\text { NMP. } 100 \mathrm{~mL}^{-1}\end{array}$} & \multicolumn{2}{|c|}{$\begin{array}{c}\text { E. coli } \\
\text { NMP.100 } \mathrm{mL}^{-1}\end{array}$} & \multicolumn{2}{|c|}{$\begin{array}{l}\text { DBO } \\
\text { mg. } .^{-1}\end{array}$} & \multicolumn{2}{|c|}{$\begin{array}{c}\text { Clorofila a } \\
\mu \mathrm{g} . \mathrm{L}^{-1}\end{array}$} \\
\hline & Média & Desvp* & Média & Desvp & Média & Desvp & Média & $\overline{\text { Desvp }}$ \\
\hline PP15 Entrada & $2.680,0$ & $3.355,6$ & 20,3 & 17,6 & 18,37 & 5,7 & 21,7 & 8,5 \\
\hline PP15 Saída & $18.184,7$ & $10.405,0$ & 48,7 & 84,3 & 17,17 & 2,0 & 13,9 & 8,5 \\
\hline PP9 Entrada & $29.736,4$ & $33.238,0$ & 137,1 & 191,3 & 15,15 & 6,4 & 9,0 & 7,8 \\
\hline PP9 Saída & $52.152,9$ & $37.468,2$ & 60,4 & 109,7 & 14,21 & 6,2 & 17,9 & 17,8 \\
\hline PP5 Entrada & $4.200,0$ & $8.231,6$ & $2.690,2$ & $8.063,2$ & 10,80 & 3,6 & 7,5 & 0,0 \\
\hline PP5 Saída & $37.071,4$ & $36.077,9$ & 308,3 & 857,8 & 26,04 & 7,0 & 175,0 & 78,1 \\
\hline PP1 Saída & $49.818,1$ & $74.174,4$ & $1.302,9$ & $2.232,4$ & 22,08 & 10,1 & 232,1 & 161,8 \\
\hline PP4 Saída & $15.946,0$ & $7.158,0$ & 591,6 & 891,6 & 15,27 & 6,2 & 61,2 & 46,4 \\
\hline PP10 Saída & $10.911,0$ & $8.661,6$ & 19,2 & 36,6 & 19,60 & 7,9 & 76,8 & 31,9 \\
\hline
\end{tabular}

*Desvp=desvio-padrão

A análise dos componentes principais (ACP) resumiu em seus 2 primeiros componentes $81,5 \%$ da variabilidade dos dados de acréscimos da DBO, E. coli, coliformes totais e clorofila a nas águas utilizadas no abastecimento e na saída dos viveiros de pesque-pague da bacia do rio Corumbataí. O componente 1 explicou $54,4 \%$ da variância total encontrada, enquanto que o componente 2 explicou 27,1\%. Os acréscimos de coliformes e pigmentos apresentaram correlação negativa com o componente 1 e o acréscimo de $E$. coli apresentou correlação negativa com o componente 2 (Tabela 3 ).

TABELA 3 - Correlação dos acréscimos de coliformes totais (Coliformes), Escherichia coli (E. coli), demanda bioquímica de oxigênio (DBO), clorofila a (Pigmentos) na água de abastecimento e efluentes de viveiros de pesque-pague da bacia do rio Corumbataí-SP.

\begin{tabular}{lcc}
\hline Variáveis & Componente 1 & Componente 2 \\
\hline Coliformes $\left(\mathrm{NMP} .100 \mathrm{~mL}^{-1}\right)$ & $\mathbf{- 0 , 6 9 5}$ & $-0,066$ \\
E. coli $\left(\mathrm{NMP} .100 \mathrm{~mL}^{-1}\right)$ & 0,292 & $\mathbf{- 0 , 9 5 3}$ \\
DBO $\left(\mathrm{mg} . \mathrm{L}^{-1}\right)$ & $\mathbf{0 , 9 0 1}$ & 0,131 \\
Pigmentos $\left(\mu \mathrm{g} . \mathrm{L}^{-1}\right)$ & $\mathbf{- 0 , 8 9 4}$ & $-0,392$ \\
\hline Variação explicada & $54,4 \%$ & $27,1 \%$ \\
\hline
\end{tabular}

Após a ordenação pela análise de componentes principais (Figura 2), o PP5E apresentou características discriminantes dos demais pesque-pague (Tabela 2), pelas elevadas médias de 
quantidades de E. coli em suas águas de abastecimento. O PP5S apresentou elevadas cargas de DBO e coliformes, fato este preocupante em consequência do manejo empregado em seus viveiros (Figura 2).

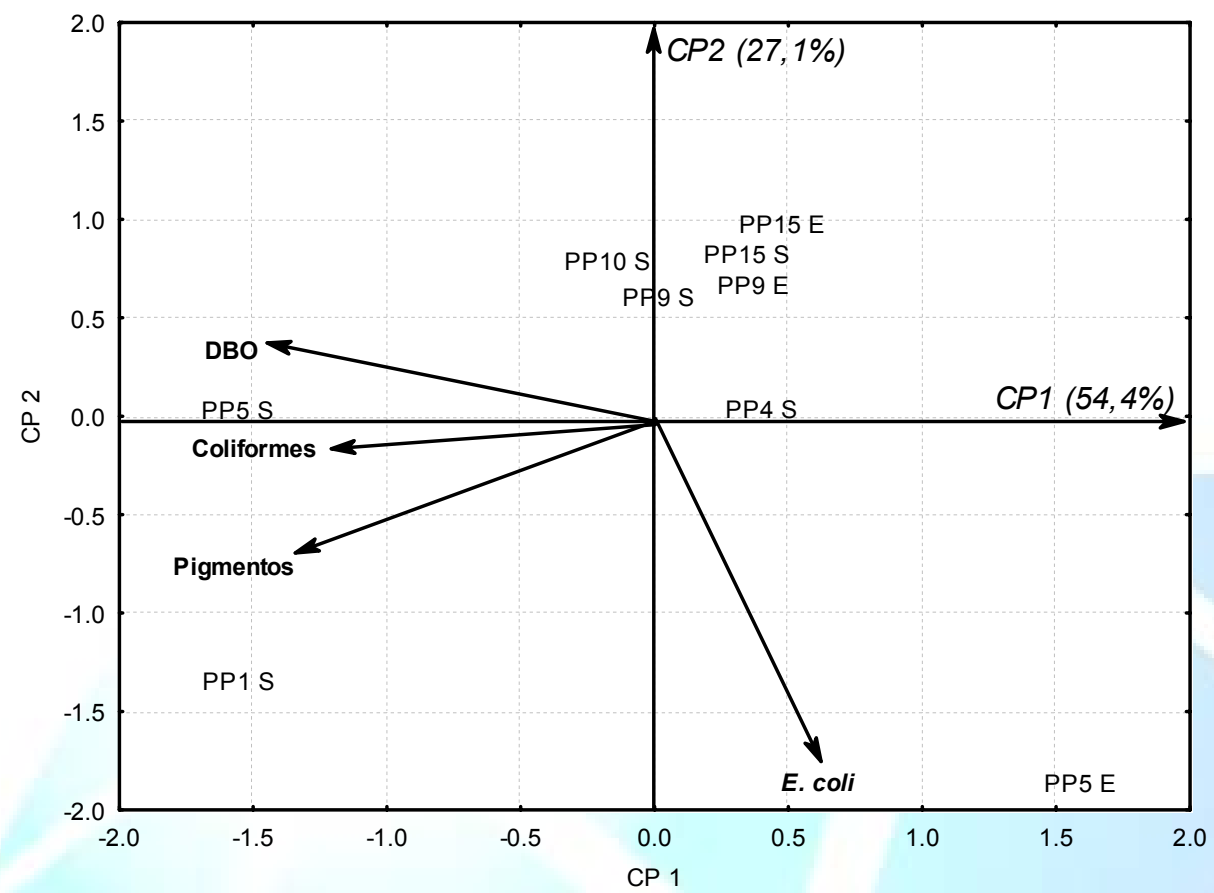

FIGURA 2. Ordenação pela ACP das variáveis bióticas dos pesque-pagues da bacia do rio Corumbataí, SP.

Para E. coli, a maioria dos pesque-pague em quase todas as coletas apresentou valores abaixo de 1.000 org. $\cdot 100 \mathrm{~mL}^{-1}$. O valor mais alto encontrado pode ser considerado anormal, visto que, em coletas posteriores, os valores observados sempre foram perto de zero. Esses resultados também não diferiram daqueles encontrados por Eler e Espíndola (2006), em que poucos pesquepague ultrapassaram o limite e cujo valor máximo foi de 10.000 org. $\cdot 100 \mathrm{~mL}^{-1} \mathrm{em}$ um dos pesque pague.

A proliferação de microrganismos, animais e vegetais heterótrofos reduzem o oxigênio dissolvido a quase zero, nos corpos hídricos. Essa proliferação depende da matéria orgânica presente no manancial, pois a presença desta reduz o oxigênio, uma vez que a maior demanda é de origem respiratória e oxidação que é realizada por via enzimática, portanto, ocorrendo aquilo que se denomina demanda bioquímica de oxigênio (DBO) (BRANCO, 1986; PORTUGAL-FILHO, 2006). Com isso, os resultados aqui encontrados podem representar grande quantidade de matéria orgânica presente dentro dos viveiros estudados, o que pode ser causado por excesso de ração, causando enriquecimento por nutrientes ou também, pela presença de fezes de animais.

Para clorofila a, os resultados demonstraram claramente o enriquecimento de nutrientes que ocorre nos viveiros. Ao comparar os valores encontrados nas águas de abastecimento dessas unidades com aqueles de seus efluentes, verifica-se aumento na concentração dessa variável no interior dos viveiros. Este resultado é relacionado, possivelmente, com o acréscimo de nutrientes que acarretou o aumento na produção primária.

Em relação ao limite estabelecido para clorofila a pela legislação vigente para água doce de classe $2\left(30 \mu \mathrm{g} . \mathrm{L}^{-1}\right)$, os resultados mais preocupantes foram encontrados no PP5 e PP1, cujos valores também ficaram acima daqueles encontrados por Tucci-Moura (1996) para o Lago das Garças, considerado eutrófico $\left(100 \mu \mathrm{g} . \mathrm{L}^{-1}\right)$. 
A situação aqui observada é preocupante nos viveiros, pois no PP1 foi encontrado valor de 523,6 $\mu \mathrm{g} . \mathrm{L}^{-1}$ em uma das coletas, o que era esperado pela coloração esverdeada. O PP1S, após a ordenação pela análise de componentes principais, apresentou médias elevadas de clorofila a, fato este esperado conforme médias encontradas para este fator (Tabela 2). Eler e Espíndola (2006), analisando a água em 2 viveiros com alta estocagem de peixes, encontraram em um deles valores de $327,4 \mu \mathrm{g} . \mathrm{L}^{-1}$, exatamente onde foi observado evento de floração de algas, que cobria metade do lago, com presença marcante de odor de "mofo" ou "BHC".

Considerando o monitoramento dos 6 pesque-pague analisados bimensalmente, pode-se concluir que os pesque-pague com valores mais preocupantes precisam de maior apoio técnico em relação ao manejo e tratar os efluentes dos viveiros para minimizar a carga que chegará ao rio. A quantidade excessiva de algas pode causar redução de oxigênio dissolvido a quase zero à noite, podendo representar também a presença de organismos patogênicos ou algas que causam sabor desagradável aos peixes (off-flavor) e odor na água.

Os testes de toxicidade realizados em todas as coletas não indicaram indícios de toxicidade aguda ao microcrustáceo Daphnia similis em nenhuma das amostras durante todo período de monitoramento. Assim como ocorreu no diagnóstico inicial, os pesque-pague monitorados durante todo o período não utilizaram componente químico ou medicamento que apresentasse qualquer toxicidade.

\section{CONCLUSÕES}

Os resultados deste estudo demonstraram que, na maioria dos pesque-pague na bacia do rio Corumbataí, os valores das variáveis bióticas estudadas indicaram carga poluidora elevada. Isso é preocupante, pois os efluentes dos pesque-pague serão carreados para os córregos próximos, e a carga poluidora, de forma direta ou indireta, contribuirá para poluir ainda mais os corpos de água superficiais. Os resultados sugerem, portanto, necessidade de tratamento dos efluentes e melhor manejo dos viveiros dos pesque-pague.

O tipo de manejo utilizado pode ser o principal responsável pela precária situação da qualidade da água dos viveiros dos pesque-pague estudados neste período; entretanto, são necessários estudos que relacionem o manejo e a qualidade da água. Nenhum dos pesque-pague atualmente em atividade na bacia do rio Corumbataí trata seus efluentes, e contribuem possivelmente para o aumento da carga poluidora no referido corpo de água. Há necessidade de estabelecimento de um Passivo Ambiental para essa atividade.

\section{AGRADECIMENTOS}

Agradecendo à FAPESP pelas bolsas de Iniciação Científicas concedidas Processo 04 06585- e a FEHIDRO pelo auxílio à pesquisa Processo FEHIDRO 476/2002

\section{REFERÊNCIAS}

APHA - AMERICAN PUBLIC HEALTH ASSOCIATION.Standard methods for the examination of water and wastewater.20th ed. Washington: American Public Health Association; AWWA; WPCF. 1998. 1569p.

BOYD, C.E.; QUEIROZ, J. Aquaculture pond effluent management.Aquaculture Asia,April-June, p. 43-46, 1997. 
BRANCO, S.M. Hidrologia Aplicada à Engenharia Sanitária. 3.ed. São Paulo: CETESB/ASCETESB. 1986. 395p.

BRASIL. Ministério do Meio Ambiente. Conselho Nacional do Meio Ambiente - CONAMA Resolução de n. $^{\circ}$ 357, de 17 de março de 2005. Dispõe sobre a classificação dos corpos de água e diretrizes ambientais. Brasília, DF; SEMA,2005. 98p.

BUFON, A.G.M. Variação temporal e espacial da taxa de sedimentação e das características limnológicas da microbacia do córrego da Barrinha, município de Pirassununga, SP.2002. $120 \mathrm{p}$.

CASTELLANI, D. Caracterização da piscicultura na região sul de São Paulo (Brasil). 2002. 79f. Dissertação (Mestrado em Conservação e Manejo de Recursos) - Centro de Estudos Ambientais, Universidade Estadual Paulista, Rio Claro, 2002.

CETESB - COMPANHIA DE TECNOLOGIA E SANEAMENTO AMBIENTAL. Água - Teste de toxicidade aguda com Daphnia similis, Lei 5.018. São Paulo: CETESB. 1991.

ELER, M.N.; ESPÍNDOLA, E.L.G. Avaliação dos impactos de pesque-pague: Uma análise da atividade na bacia hidrográfica do rio Mogi-Guaçu. São Carlos. Editora Rima. 2006. 312p.

KUBITZA, F. Qualidade da água no cultivo de peixes e camarões. Jundiaí: Degaspari, 2003. $226 \mathrm{p}$.

MARKER, A.F.H.; NUSCH, E.A.; RAI, H.; RIEMANN, B.The measurement of photosynthetic pigments in freshwaters and standardization of methods: conclusions and recommendations. ArchivfürHydrobiologie-BeiheftErgebnisse der Limnologie.v.14, p.91-106. 1980.

ONO, E.A. ; KUBITZA, F. Cultivo de peixes em tanques redes. 2.ed. Jundiaí. 1999. 68p.

PÁDUA, H.B. Impacto ambiental: um impacto na aqüicultura. Revista Brasileira de Agropecuária, v.1, n.12, p.1-66, 2001.

PORTUGAL-FILHO, G.; GPCA - Meio Ambiente. Disponível em: $<$ http://www.gpca.com.br/poluicao2.htm> (acesso em: 14 Jul. 2006).

SANTOS, A.A.O. Fatores abióticos e sócio-econômicos de pesque-pague da bacia do rio Corumbataí, TCC ( Ciências Biológicas). UNESP, Campus de Rio Claro.2006.144p.

STATSOFT, INC. STATISTICA (data analysis software system), version 7.1.www.statsoft.com 2005 .

TAUK-TORNISIELO, S.M. Pesque-pague. Bacia do rio Corumbataí. Rio Claro: Centro de Estudos Ambientais, UNESP, Campus de Rio Claro, 2010, 126p.

TUCCI-MOURA, A.T.N. Estrutura e dinâmica da comunidade fitoplanctônica numa lagoa eutrófica, São Paulo, SP, Brasil, a curtos intervalos de tempo: comparação entre épocas de chuva e seca. Dissertação (Mestrado) - Universidade Estadual Paulista, Rio Claro. 1996. 